\title{
Feeding hydrogenated palm fatty acids and rumen-protected protein to lactating Holstein-Friesian dairy cows modifies milk fat triacylglycerol composition and structure, and solid fat content
}

\author{
Sara Pacheco-Pappenheim, ${ }^{1} \oplus$ Sine Yener, ${ }^{1} \odot$ Kelly Nichols, ${ }^{2} \oplus$ Jan Dijkstra, ${ }^{2} \odot$ Kasper Hettinga, ${ }^{1 *} \odot$ \\ and Hein J. F. van Valenberg ${ }^{1}$ (D) \\ ${ }^{1}$ Dairy Science and Technology Group of Food Quality and Design (FQD), Wageningen University and Research, PO Box 17, 6700 AA, \\ Wageningen, the Netherlands \\ ${ }^{2}$ Animal Nutrition Group, Wageningen University and Research, PO Box 338, $6700 \mathrm{AH}$, Wageningen, the Netherlands
}

\begin{abstract}
The aim of this study was to analyze the effect of fat and protein supplementation to dairy cattle rations on milk fat triacylglycerol (TAG) composition, fatty acid (FA) positional distribution in the TAG structure, and milk solid fat content (SFC). Fifty-six lactating Holstein-Friesian cows were blocked into 14 groups of 4 cows and randomly assigned 1 of 4 dietary treatments fed for $28 \mathrm{~d}$ : (1) low protein, low fat, (2) high protein, low fat, (3) low protein, high fat, and (4) high protein, high fat. The high protein and high fat diets were obtained by isoenergetically supplementing the basal ration (low protein, low fat) with rumen-protected soybean meal and rumen-protected rapeseed meal, and hydrogenated palm FA (mainly C16:0 and C18:0), respectively. Fat supplementation modified milk TAG composition more extensively compared with protein supplementation. Fat supplementation resulted in decreased concentrations of the low molecular weight TAG carbon number (CN) 26 to CN34 and medium molecular weight TAG CN40, CN44, and CN46, and increased concentrations of CN38 and the high molecular weight TAG CN50 and CN52. Increased contents of C16:0, C18:0, and C18: 1cis-9 in TAG in response to fat supplementation were related to increases in the relative concentrations of $\mathrm{C} 16: 0$ and $\mathrm{C} 18: 0$ at the $s n-2$ position and $\mathrm{C} 18: 0$ and C18:1cis-9 at the $s n-1(3)$ positions of the TAG structure. Increased concentrations of high molecular weight TAG species CN50 and CN52 in response to fat supplementation was associated with increased milk SFC at 20,25 , and $30^{\circ} \mathrm{C}$. Our study shows that important alterations in milk TAG composition and structure occur when feeding hydrogenated palm FA to lactating dairy cattle, and that these alterations result in an increased
\end{abstract}

Received July 29, 2021.

Accepted January 6, 2022.

*Corresponding author: kasper.hettinga@wur.nl
SFC of milk fat. These changes in milk SFC and TAG composition and structure may improve absorption of both fat and minerals in milk-based products for infants and may affect processing of milk fat.

Key words: palm fatty acid supplementation, triglyceride profile, fatty acid regiospecific distribution, saturated long-chain fatty acids

\section{INTRODUCTION}

Bovine milk fat is mainly composed of triacylglycerols (TAG; 98\%), which are formed by the esterification of 3 fatty acids (FA) to a glycerol backbone. Milk FA composition can be modified by various nutritional interventions to dairy cattle rations to serve a functional purpose [e.g., to improve the processing and manufacturing of milk and dairy products, or alter the nutritional value of milk to benefit human health (Jenkins and McGuire, 2006; Mohan et al., 2021)]. The supplementation of saturated long-chain FA (SLCFA) into dairy cattle rations is a nutritional strategy commonly used to increase the energy density of the diet in support of milk production (Ashes et al., 1997; Nichols et al., 2018). In contrast to UFA that are susceptible to biohydrogenation in the rumen (Baumgard et al., 2000), SLCFA are largely rumen-inert, and commonly do not result in negative effects on fiber digestibility or milk fat depression at supplementation levels up to $3 \%$ of dietary DM (Ashes et al., 1997; NRC, 2001; Nichols et al., 2018). Milk fat content and FA composition will vary depending on the type and amount of supplemented fat and its relative inertness in the rumen (Jacobs et al., 2011; Rabiee et al., 2012).

Variation in the composition of FA available for milk fat synthesis causes changes in milk TAG composition (Jensen, 2002; Pacheco-Pappenheim et al., 2019). Previous studies have reported that oil supplementation to dairy cattle rations (e.g., palm oil, canola oil, olive oil, soy oil, and linseed oil) decreased the milk concentration 
of TAG species containing 30 to 36 and 42 to 46 carbon atoms, and increased the concentration of TAG species containing 50 to 54 carbon atoms, as a result of the high concentrations of long-chain FA (LCFA) in the supplemented oils (Banks et al., 1989; DePeters et al., 2001). Seasonal variation in feeding regimens also affects milk TAG composition, with increased concentrations of high molecular weight (HMW) TAG and decreased concentrations of low molecular weight (LMW) and medium molecular weight (MMW) TAG upon intake of fresh grass in spring and summer (Pacheco-Pappenheim et al., 2021). Variations in milk TAG composition may in turn affect the solid fat content (SFC) of milk fat (Precht and Frede, 1994; Ashes et al., 1997). The $\mathrm{SFC}$ at a certain temperature is responsible for the mouthfeel and texture characteristics of a food product (e.g., softness, hardness, spreadability, and room temperature stability of butter; NorAini et al., 1995; Mohan et al., 2021). Therefore, milk SFC is considered one of the key parameters that defines the suitability of a fat source for a specific food product application. Earlier studies have suggested that high proportions of UFA in dairy cow diets increased UFA esterification in HMW TAG species, resulting in lower milk fat SFC (Smet et al., 2010; Larsen et al., 2014). Most of the studies on this topic have assessed the effect of unsaturated fats (rumen-protected and nonprotected sources) on milk SFC, whereas scarce information can be found on the effect on milk SFC when feeding saturated fats (e.g., supplementation of SLCFA) to dairy cattle (Ashes et al., 1997). Indeed, the melting characteristics of milk fat with respect to the firmness of butter and the feeding of palm FA to dairy cattle recently garnered extensive media attention (Harvatine, 2021; Marangoni and Ghazani, 2021). This controversy brought to light the necessity for further studies investigating the link between nutritional interventions for dairy cattle and their effect on relevant milk fat characteristics for dairy food processing and technology.

The structure of TAG species changes according to the enzymatically driven positional distribution of FA on the glycerol backbone (Jensen, 2002). The stereospecific numbering $(\boldsymbol{s n})$ identifies the position of the FA in the TAG structure, where $s n-1(3)$ refers to the primary positions and $s n-2$ to the secondary position in the TAG structure. There is great interest in the composition of the FA in the secondary position in the TAG structure, particularly in relation to C16:0. For example, a higher content of $\mathrm{C} 16: 0$ at the $s n-2$ position in infant formula has been shown to increase free FA and calcium absorption in infants (Innis, 2011; Yaron et al., 2013). Tzompa-Sosa et al. (2014) showed that differences in the total FA composition in milk fat were related to the FA positional distribution in the TAG structure, where high concentrations of C16:0 in milk fat were associated with decreased proportions of C14:0, C16:0, and SLCFA and an increased proportion of $\mathrm{C} 18: 1$ cis-9 at the $s n-2$ position in the TAG structures. Increased concentrations of UFA from canola oil (containing mainly MUFA) in the diet of cows reduced the concentration of $\mathrm{C} 16: 0$ and increased the concentration of C18:1 cis-9 at the sn-2 position (DePeters et al., 2001). To our knowledge, no information has been reported on the effect of saturated fat supplementation to dairy cattle on the esterification preference of C16:0 at the $s n-2$ position in the TAG structure of milk fat.

Nichols et al. (2018) reported an increase in the concentration of $\mathrm{C} 16: 0$ and $\mathrm{C} 18: 0$ in the milk fat of dairy cattle supplemented with dietary hydrogenated palm FA compared with nonsupplemented cattle. Considering this observation in the interest of food processing and dairy product design, we used milk samples collected from the study of Nichols et al. (2018) to investigate the effect of rumen-inert SLCFA from hydrogenated palm FA supplemented to dairy cattle on TAG composition, FA positional distribution in the TAG structure, and SFC of milk fat. We hypothesized that supplementing SLCFA in dairy cattle rations may support the formation of TAG species with C16:0 at the $s n-2$ position, which is beneficial for the development of infant formula. Further, we expected that rations rich in C16:0 may increase the level of saturated TAG species in milk fat, resulting in an increased SFC. This consequence may negatively affect the mouthfeel and texture characteristics of dairy products, thus requiring adjustments in the processing conditions of products made from this milk fat.

\section{MATERIALS AND METHODS}

\section{Milk Sample Collection and Preparation}

Milk samples were collected from 56 Holstein-Friesian cows $(167 \pm 87$ DIM; $2.8 \pm 1.9$ lactations; mean $\pm \mathrm{SD} ; 20$ primiparous, 36 multiparous) enrolled in a feeding study that has been previously described by Nichols et al. (2018). Briefly, the experiment consisted of 2 successive 28-d periods (control and experimental), each consisting of $21 \mathrm{~d}$ of diet adaptation and $7 \mathrm{~d}$ of measurement. A basal TMR consisting of $34 \%$ grass silage, $33 \%$ corn silage, $5 \%$ grass hay, and $28 \%$ concentrate (DM basis) was fed during the control period. Cows were blocked (4 cows per block) based on parity, DIM, and DMI during the final $7 \mathrm{~d}$ of the control period, and were randomly assigned within block to 1 of 4 treatments for the experimental period: (1) low 
protein, low fat (LP-LF), (2) high protein, low fat (HP-LF), (3) low protein, high fat (LP-HF), and (4) high protein, high fat (HP-HF). The LP and HP diets contained on average 15.4 and $17.7 \% \mathrm{CP}$, respectively, on a DM basis. The LF and HF diets contained on average 3.9 and $7.5 \%$ crude fat, respectively, on a DM basis (Nichols et al., 2018). The HP and HF diets were obtained by restricting the intake of the basal TMR of individual cows by $5 \%$ of their ad libitum intake during the control period and supplementing $2.0 \mathrm{~kg}$ of rumen-protected soybean meal and rapeseed meal (DM basis; 50:50 mixture of SoyPass + RaPass; Borregaard LignoTech) and $0.68 \mathrm{~kg}$ of rumen-inert hydrogenated palm FA (DM basis; 50\% C16:0 and 47\% C18:0; Hidropalm; Norel), respectively. Cows were housed in a freestall barn and had ad libitum access to water. The TMR were mixed and distributed once daily at 1000 $\mathrm{h}$ via electronic intake control boxes (Insentec). Cows were milked twice daily at 530 and $1630 \mathrm{~h}$.

Milk samples from individual cows were collected at 2 subsequent morning $(530 \mathrm{~h})$ and afternoon milkings $(1630 \mathrm{~h})$ in the final $7 \mathrm{~d}$ of each period and stored at $-20^{\circ} \mathrm{C}$ pending milk fat extraction. Milk fat was extracted based on the method described by TzompaSosa et al. (2014) with some modification. Briefly, frozen milk samples were thawed in a water bath $\left(37^{\circ} \mathrm{C}\right.$ for approximately $30 \mathrm{~min}$ ), and $50 \mathrm{~mL}$ of each sample was pooled for each cow into a composite sample for milk fat extraction. The cream portion was separated by centrifugation $\left(1,643 \times g\right.$ for $5 \mathrm{~min}$ at $\left.4^{\circ} \mathrm{C}\right)$. Fat was extracted by treating the cream with $4 \mathrm{M} \mathrm{HCl}$, heating $\left(70^{\circ} \mathrm{C}\right.$ for 30 min under gentle shaking), and centrifuging $\left(1,643 \times g\right.$ for $5 \mathrm{~min}$ at $\left.4^{\circ} \mathrm{C}\right)$ to remove protein traces. A final heating step was performed $\left(70^{\circ} \mathrm{C}\right.$ for 15 min under gentle shaking) to remove traces of water. Milk fat samples were stored at $-20^{\circ} \mathrm{C}$ until further analysis.

\section{Triacylglycerol Composition Analysis}

Triacylglycerol composition was analyzed by GCflame ionization detector (FID) and MALDI-TOFMS. The GC-FID was used to determine the TAG composition of even-chain TAG groups. A TAG group is composed of TAG species with same number of total carbon atoms [i.e., the same carbon number $(\mathbf{C N})$ ]. The molecular weight of each individual TAG species was determined using MALDI-TOF-MS, which determines the TAG profile (even- and odd-chain TAG species) based on their carbon number and number of double bonds (DB). Both methods (GC-FID and MALDI-TOF-MS) complement each other, resulting in a complete overview of milk TAG composition (Schiller et al., 2004; Pacheco-Pappenheim et al., 2021).

\section{GC-FID}

Triacylglycerol composition of milk fat samples from the control $(\mathrm{n}=56)$ and experimental $(\mathrm{n}=56)$ periods (total $n=112$ ) were determined according to the ISO Standard 17678 (ISO, 2010) for GC-FID using a column injector port (Thermo Trace GC ultra; Thermo Scientific) and a UltiMetal CP7532 column (5 $\mathrm{m} \times 0.53 \mathrm{~mm}$ i.d. $\times 0.17 \mu \mathrm{m}$ film thickness; Varian) Triacylglycerols were classified according to their carbon number. Anhydrous milk TAG standard (BCR519; Sigma-Aldrich Chemie $\mathrm{GmbH}$ ) was used as a reference for the identification of all TAG groups. Triacylglycerol composition was expressed as the relative concentration of the total TAG composition (g/100 $\mathrm{g}$ of total TAG). The TAG groups that can be identified with this method are even-chain TAG from CN24 to CN54.

\section{MALDI-TOF-MS}

Triacylglycerol composition with MALDI-TOF-MS (UltrafleXtreme, Bruker Corporation) was determined in milk fat samples from the experimental period $(\mathrm{n}=$ 56) according to the methods described by TzompaSosa et al. (2018) and Yener and van Valenberg (2019). Each sample was plated 5 times and subjected to 1,000 laser pulses taken randomly (automatic mode) from 20 different points to allow the random acquisition of masses. The obtained mass spectra were analyzed according to Yener and van Valenberg (2019) with the MALDIquant package using $\mathrm{R}$ (Gibb and Strimmer, 2012). Selection of the mass peaks was done using a signal-noise ratio $>6$. The relative intensities were calculated by dividing the intensity of each mass peak with the sum of the intensity of all mass peaks and are expressed as a percentage. This was performed for each of the 5 repetitions, and the mean values were used as the relative intensity for each TAG species. For identification of TAG species, the molecular weights of TAG species measured with MALDI-TOF-MS were matched in the LIPID MAPS Online Tools library to the molecular weight of TAG species with a known CN:DB (Fahy et al., 2005).

\section{Regiospecific Distribution Analysis of FA}

The composition of FA at the $s n-2$ position of the TAG structure was analyzed in milk fat samples from cows receiving the LP-LF and LP-HF treatments in the experimental period $(n=28)$ to investigate the effect of dietary supplementation with only palm FA. The $s n-2$ positional analysis was performed via enzymatic transesterification using Candida antarctica lipase (fraction B; 10,000 PLU/g, Novozym 435; Novozymes A/S) ac- 
cording to the JOCS/AOCS Joint Method Ch 3a-19 (AOCS, 2019). After enzymatic transesterification, the 2-monoacylglycerol fraction was isolated and analyzed for FAME composition. The FAME were prepared according to ISO Standard 15884 (ISO, 2002) and analyzed according to ISO Standard 16958 (ISO, 2015) with GC-FID, as described by Pacheco-Pappenheim et al. (2021). The FA profile at the $s n-2$ position was first expressed as a weight percentage $(\mathrm{g} / 100 \mathrm{~g}$ of total FA) by dividing each FA peak area by the total peak area, and was then transformed to a molar percentage. Because we used a regiospecific distribution analysis, no distinctions could be made between the FA profiles at the $s n-1$ and $s n-3$ positions in the TAG structures. For this reason, the FA profile at $s n-1(3)$ refers to the sum of the FA identified at the $s n-1$ and $s n-3$ positions. The positional distribution of FA in the TAG structure was examined according to the intra- and interpositional distributions (Tzompa-Sosa et al., 2014).

Intrapositional Distribution. Intrapositional distribution refers to the relative concentrations or abundance of a FA at the $s n-2$ and $s n-1(3)$ positions in the TAG structure.

The $s n-2$ position is the FA profile analyzed at the $s n-2$ position expressed in molar percentage.

The $s n-1(3)$ position is as follows:

$s n-1(3)_{\mathrm{FA} i}$ position $=\left(\mathrm{TAG}_{i} \times 3-s n-2_{\mathrm{FA} i}\right.$ position $) / 2$,

where $s n-1(3)_{\mathrm{FA} i}$ position is the molar percentage of a specific FA $(i)$ estimated to be at these positions, TAG $_{i}$ is the molar percentage of a specific FA $(i)$ in milk TAG transformed from the relative concentrations in $\mathrm{g} / 100$ $\mathrm{g}$ of FA reported by Nichols et al. (2018), and $s n-2$ FA $i$ position is the molar percentage of a specific FA $(i)$ analyzed at the $s n-2$ position.

Interpositional Distribution. Interpositional distribution refers to the proportions of a FA over the 3 positions in the TAG structure. The intrapositional distribution of FA at the $s n-2$ and $s n-1(3)$ positions in the TAG structure was used to calculate the FA proportions over these positions in the TAG structure. The equations to calculate the FA proportions at each position are

$$
\begin{gathered}
s n-2_{\mathrm{FA} i}(\%)=\left\{s n-2_{\mathrm{FA} i} \text { position } /\left[s n-2_{\mathrm{FA} i}\right. \text { position }\right. \\
\left.\left.+\left(s n-1(3)_{\mathrm{FA} i} \text { position } \times 2\right)\right]\right\} \times 100, \\
s n-1(3)_{\mathrm{FA} i}(\%)=\left\{\left(s n-1(3)_{\mathrm{FA} i} \text { position } \times 2\right) /\right. \\
\left.\left[s n-2_{\mathrm{FA} i} \text { position }+\left(s n-1(3)_{\mathrm{FA} i} \text { position } \times 2\right)\right]\right\} \times 100,[3]
\end{gathered}
$$

where $s n-2_{\mathrm{FA} i}(\%)$ is the proportion of a specific FA $(i)$ estimated at the $s n-2$ position and $s n-1(3)_{\mathrm{FA} i}(\%)$ is the proportion of a specific FA (i) estimated at the $s n-1(3)$ position.

\section{Solid Fat Content Analysis}

The SFC analysis was performed for all samples $(\mathrm{n}=$ $112)$ at 6 measuring temperatures $(0,10,20,25,30$, and $40^{\circ} \mathrm{C}$ ) by nuclear magnetic resonance (NMR; Bruker mq20 minispec NMR analyzer; Bruker) according to the AOCS Official Method Cd 16b-93 (AOCS, 2017). The NMR analyzer was set at a frequency of 19.95 $\mathrm{MHz}$, a dead time of $0.0073 \mathrm{~ms}$, and a cell temperature of $40^{\circ} \mathrm{C}$. Milk fat samples were completely melted in a water bath at $40^{\circ} \mathrm{C}$, and $1 \mathrm{~g}$ of liquid milk fat was transferred into a NMR glass tube (diameter of $10 \mathrm{~mm}$, length of $150 \mathrm{~mm}$, wall thickness of $0.6 \mathrm{~mm}$; Bruker Nederland B.V.). The tubes were heated to $100^{\circ} \mathrm{C}$ for $15 \mathrm{~min}$ followed by $15 \mathrm{~min}$ at $60^{\circ} \mathrm{C}$. To complete the tempering, the tubes were cooled to $0^{\circ} \mathrm{C}$ for $60 \mathrm{~min}$. Once cooled, the first measurement was done at $0^{\circ} \mathrm{C}$. Samples were held for $30 \pm 1 \mathrm{~min}$ at each measuring temperature before the SFC analysis took place.

\section{Statistical Analysis}

The effect of supplemented protein, fat, and their interaction on milk TAG composition, the FA positional distribution in TAG, and SFC were analyzed using the MIXED procedure of SAS/STAT version 9.4 (SAS Institute Inc.). Variances in milk TAG composition analyzed by GC-FID and SFC were assessed according to model 1:

$$
\begin{gathered}
\mathrm{Y}_{\mathrm{ijkl}}=\mu+\beta \mu_{1}+\text { block }_{\mathrm{i}}+\text { Protein }_{\mathrm{j}}+\text { Fat }_{\mathrm{k}} \\
+(\text { Protein } \times \text { Fat })_{\mathrm{jk}}+\varepsilon_{\mathrm{ijkl}},[\text { model } 1]
\end{gathered}
$$

where $Y_{i j k l}$ are individual observations, $\mu$ is the overall mean, $\beta$ is the parameter measured in the control period (covariate parameter; i.e., TAG composition analyzed by GC-FID or SFC), $\mu_{1}$ is the observed TAG composition or SFC in the control period of cow 1, block $_{\mathrm{i}}$ is the random block effect ( $\mathrm{i}=1$ to 14 ), Protein $_{\mathrm{j}}$ is the fixed protein effect ( $\mathrm{j}=1$ to 2$), \mathrm{Fat}_{\mathrm{k}}$ is the fixed fat effect $(\mathrm{k}$ $=1$ to 2$)$, $(\text { Protein } \times \text { Fat })_{\mathrm{jk}}$ is the interaction between fixed protein and fat effects, and $\varepsilon_{\mathrm{ijkl}}$ is the residual random error term.

Because only samples from the experimental period were analyzed by MALDI-TOF-MS for TAG composition, this variance was assessed according to model 2 that excluded the control period covariate parameter: 


$$
\begin{aligned}
\mathrm{Y}_{\mathrm{ijk}} & =\mu+\text { block }_{\mathrm{i}}+\text { Protein }_{\mathrm{j}}+\text { Fat }_{\mathrm{k}} \\
& +(\text { Protein } \times \text { Fat })_{\mathrm{jk}}+\varepsilon_{\mathrm{ijk}} \quad[\text { model 2] }
\end{aligned}
$$

where $Y_{i j k}$ are individual observations, $\mu$ is the overall mean, block $\mathrm{i}_{\mathrm{i}}$ is the random block effect ( $\mathrm{i}=1$ to 14 ), Protein $_{\mathrm{j}}$ is the fixed protein effect ( $\mathrm{j}=1$ to 2$), \mathrm{Fat}_{\mathrm{k}}$ is the fixed fat effect $(\mathrm{k}=1$ to 2$)$, (Protein $\times$ Fat $)_{\mathrm{jk}}$ is the interaction between fixed protein and fat effects, and $\varepsilon_{i j k}$ is the residual random error term.

The FA positional distribution in TAG was assessed according to model 3 that excluded the control period covariate parameter and fixed protein effect:

$$
\mathrm{Y}_{\mathrm{ik}}=\mu+\text { block }_{\mathrm{i}}+\text { Fat }_{\mathrm{k}}+\varepsilon_{\mathrm{ik}}, \quad[\text { model 3] }
$$

where $Y_{i k}$ are individual observations, $\mu$ is the overall mean, block $_{\mathrm{i}}$ is the random block effect ( $\mathrm{i}=1$ to 14 ), Fat $_{\mathrm{k}}$ is the fixed fat effect ( $\mathrm{k}=1$ to 2$)$, and $\varepsilon_{\mathrm{ik}}$ is the residual random error term.

Differences were considered significant at $P<0.050$. When a protein $\times$ fat interaction was detected at $P \leq$ 0.050, the Tukey-Kramer method was used to perform multiple comparison between treatment means for the TAG composition analyzed by GC-FID and MALDITOF MS and the SFC. Pearson correlation analysis was performed between the FA and TAG composition results measured by GC-FID using $\mathrm{R}$ version 3.6.1 (2019). A one-sample $t$-test was performed to confirm the FA stereolocation preference comparing the interpositional distribution $(\% \mathrm{~mol})$ with the hypothetical proportions at the $s n-2(33.33 \%)$ and $s n-1(3)(66.67 \%)$ positions in the TAG structures.

\section{RESULTS AND DISCUSSION}

\section{Variation in TAG Composition}

Palm-derived fat sources are commonly supplemented to increase the energy density of dairy cattle diets in support of milk production (Ashes et al., 1997; Nichols et al., 2018). Consumption of hydrogenated palm FA increased arterial plasma concentrations of LCFA (both nonesterified FA and TAG), and increased mammary gland uptake of LCFA (Nichols et al., 2019). Our results show that milk TAG composition as analyzed by GC-FID was affected independently by supplementation with protein and fat, with a protein $\times$ fat interaction affecting only TAG CN42 $(P=0.049$; Table 1$)$, which increased in response to protein supplementation but only in the absence of fat supplementation. The relative concentrations of 11 TAG groups were affected by fat supplementation, whereas only 4 TAG groups were affected by protein supplementation. In response to fat, the relative concentrations of most LMW TAG
(CN26-CN34) and the MMW TAG CN40, CN44, and CN46 decreased $(P \leq 0.023)$ and the concentrations of CN38 and the HMW TAG CN50 and CN52 increased $(P \leq 0.011$; Table 1). Our results are in line with Banks et al. (1989) where palm oil rich in C16:0 decreased concentrations of LMW and MMW TAG and increased concentrations of HMW TAG in milk fat of dairy cattle.

Similar findings were observed for the LMW TAG species whether they were analyzed by GC-FID or MALDI-TOF-MS (Figure 1; Supplemental Table S1, https://doi.org/10.4121/18318725.v1). However, opposite to GC-FID, the MALDI-TOF-MS analysis resulted in more significant protein $\times$ fat interactions for most MMW and HMW TAG species $(P \leq 0.049$; Supplemental Table S1). When grouping the TAG species according to their TAG molecular weight, protein supplementation increased the abundance of the MMW TAG group and decreased the abundance of the HMW TAG group, but only in the absence of fat supplementation (Supplemental Table S1). Protein $\times$ fat interactions affected the saturation degree of LMW, MMW, and HMW TAG groups. In the absence of fat supplementation, protein supplementation increased the abundance of monounsaturated LMW and polyunsaturated MMW TAG species and decreased the abundance of saturated and monounsaturated HMW TAG species when considered as TAG groups (Figure 1; Supplemental Table S1). These interactions were only found by MALDITOF-MS analysis and not by GC-FID, which may be explained by the fact that MALDI-TOF-MS differentiates between saturation degrees of TAG species.

Variations in TAG composition in response to fat supplementation as shown by GC-FID and MALDITOF-MS are related to the changes in milk FA composition that were previously reported by Nichols et al. (2018), where hydrogenated palm FA supplementation increased the concentrations of $\mathrm{C} 16: 0$ and $\mathrm{C} 18: 0$ in milk fat, but also decreased the concentrations of de novo synthesized FA (C6:0 to C14:0) and PUFA. Gresti et al. (1993) and Liu et al. (2020) identified that LMW and MMW TAG species were mainly composed of C6:0 to C16:0 and C18:1 FA. Using Pearson correlation analysis, we identified positive correlations $(\mathrm{r} \geq 0.47 ; P<$ 0.050) between de novo FA C8:0 to C12:0, C14:0, and C15:0 and LMW TAG CN28 to CN34 and MMW TAG CN42 to CN46. In contrast, $\mathrm{C} 16: 0$ and $\mathrm{C} 18: 1$ cis-9 were negatively correlated $(\mathrm{r} \leq-0.28 ; P<0.050)$ with most of these TAG (Supplemental Table S2, https:// doi.org/10.4121/18318725.v1). Considering the results of this correlation analysis, and the fact that LMW and MMW TAG species are mainly composed of de novo synthesized FA, it is likely that the decreased concentrations of de novo FA in response to fat supplementation lowered their availability for esterification in the 
Table 1. Milk fat triacylglycerol (TAG) composition (g/100 g of TAG) of lactating dairy cows supplemented with protein and fat as analyzed by GC-flame ionization detector

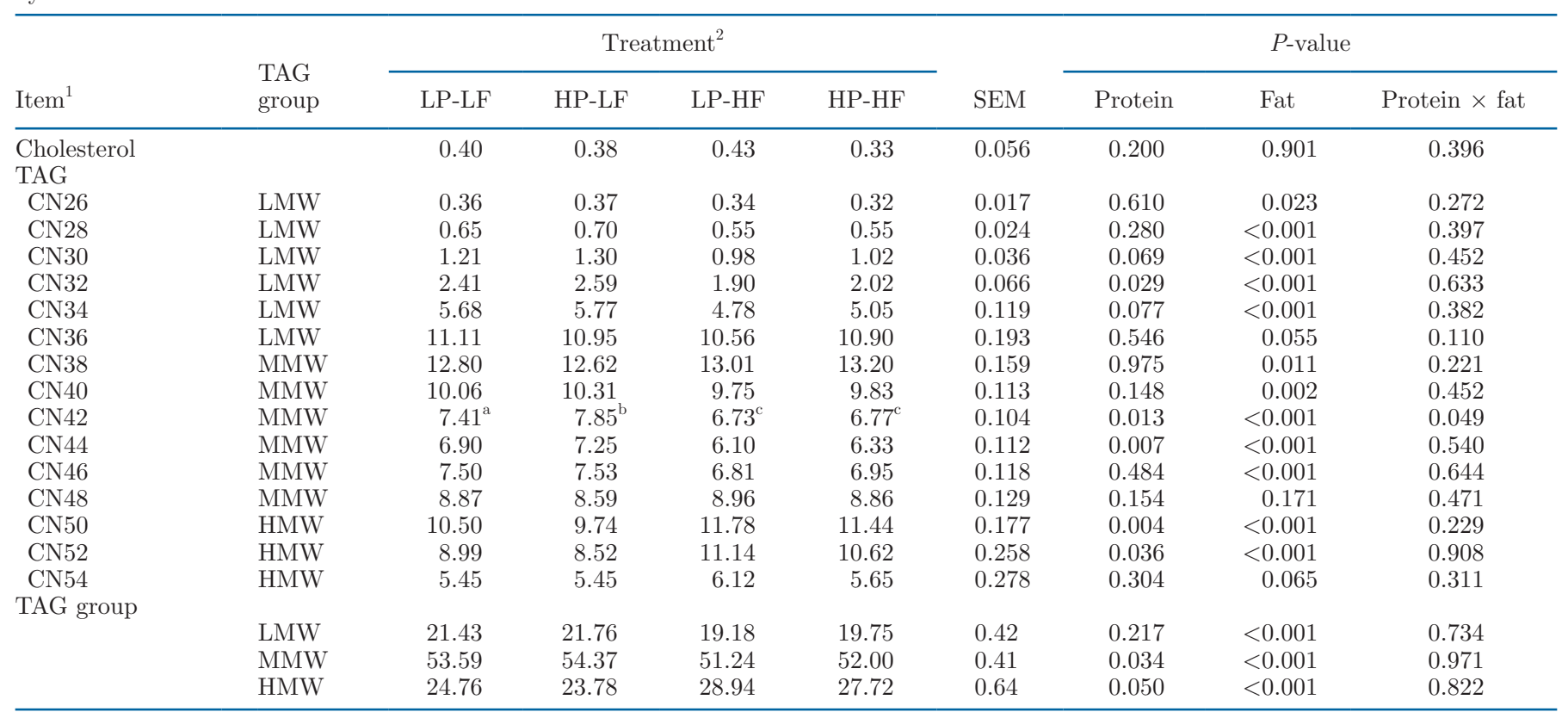

${ }^{\mathrm{a}-\mathrm{c}}$ Means in the same row with no common superscripts differ $(P<0.050)$ according to a protein $\times$ fat interaction.

${ }^{1} \mathrm{CN}=$ carbon number.

${ }^{2} \mathrm{LP}-\mathrm{LF}=$ low protein, low fat; HP-LF = high protein, low fat; LP-HF = low protein, high fat; HP-HF = high protein, high fat. High protein supplementation consisted of a 50:50 mixture of rumen-protected soybean meal and rapeseed meal. High fat supplementation consisted of rumeninert hydrogenated palm fatty acids. For all treatments $\mathrm{n}=14$.

TAG structures and thus decreased the formation of most LMW and MMW TAG species (Table 1; Figure 1; Supplemental Table S1). The HMW TAG species that increased in response to fat supplementation (Table 1; Figure 1; Supplemental Table S1) were previously identified to be mainly composed of C14:0, C16:0, C18:0, and C18:1 FA (Gresti et al., 1993; Liu et al., 2020). This suggests that the higher availability of several FA, particularly C16:0 and C18:0, in response to fat supplementation contributed significantly to the formation of most HMW TAG species (saturated, monounsaturated, and polyunsaturated) in the mammary gland. This is supported by the positive correlations ( $\mathrm{r} \geq 0.53$; $P<$ 0.050) between C18:0 and C18:1cis-9, and the HMW TAG CN52 and CN54 (Supplemental Table S2).

Protein supplementation in this study increased the concentration of de novo FA and PUFA in milk (Nichols et al., 2018). These authors suggested that de novo FA synthesis was supported by protein supplementation through mammary cell metabolism of AA into $\alpha$-ketoacids to produce acetyl-CoA, which is a precursor for the formation of de novo FA. The increased concentrations of de novo FA and PUFA in response to protein may have enhanced the formation of most monounsaturated LMW and polyunsaturated MMW TAG species, but this appears to have occurred only in the absence of fat supplementation (Supplemental
Table S1). Nichols et al. (2018) also reported that protein supplementation, in the absence of fat supplementation, tended to decrease the concentration of C16:0, which in turn could have led to the decreased formation of saturated and monounsaturated HMW TAG species (Supplemental Table S1; Gresti et al., 1993; Liu et al., 2020).

In general, our results show that fat supplementation from hydrogenated palm FA into dairy cattle rations had a greater effect on milk TAG composition than protein supplementation from rumen-protected soybean meal and rumen-protected rapeseed meal. Protein supplementation increased the abundance of monounsaturated LMW and polyunsaturated MMW TAG species and decreased the abundance of saturated and monounsaturated HMW TAG species, but usually only in the absence of fat supplementation. Fat supplementation decreased the relative intensity of most saturated, monounsaturated, and polyunsaturated LMW and MMW TAG species, and increased the relative intensity of most saturated, monounsaturated, and polyunsaturated HMW TAG species in milk fat. These changes in milk TAG composition may influence the structure of dairy-based food products rich in fat by changing the SFC of milk fat (e.g., firmness of butter; Harvatine, 2021; Marangoni and Ghazani, 2021). The effects of hydrogenated palm FA supplementation in 


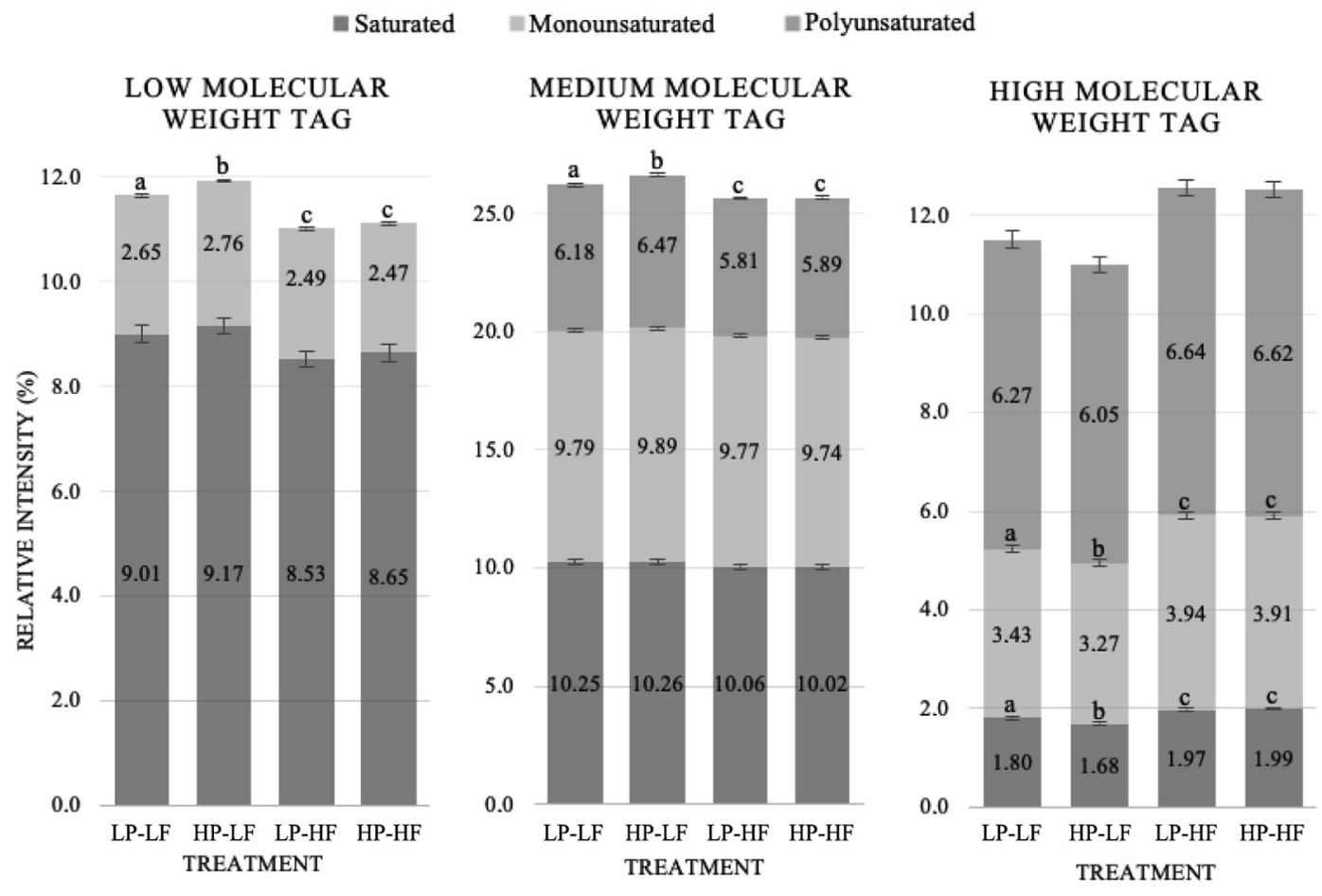

Figure 1. Low, medium, and high molecular weight triacylglycerol (TAG) species composition (relative intensity, \%) of milk fat from lactating dairy cows supplemented with protein and fat as analyzed by MALDI-TOF-MS. Different letters $(\mathrm{a}-\mathrm{c})$ in the columns indicate protein $\times$ fat interaction differences $(P<0.050)$ between treatments for the saturated, monounsaturated, and polyunsaturated species in each TAG group. The $P$-values for the main effects of protein and fat and protein $\times$ fat interactions on TAG groups and individual TAG species are presented in Supplemental Table S1. The treatment refers to the 4 diets assigned to the lactating dairy cows in the experimental period: low protein, low fat (LP-LF); high protein, low fat (HP-LF); low protein, high fat (LP-HF); and high protein, high fat (HP-HF). Fourteen cows were considered for each treatment. Error bars indicate SE of the solution of the mixed model Eq. [2].

dairy cattle rations on the SFC of milk found in this study are discussed in the section on variation in SFC.

\section{Variation in Positional Distribution of FA in the TAG}

In addition to variation in TAG composition in response to fat and protein supplementation, changes in the TAG structure may occur. A high content of C16:0 in milk fat has been reported to influence the proportion of this FA at the $s n-2$ position in TAG structures (Tzompa-Sosa et al., 2014). Therefore, we analyzed whether supplementation of hydrogenated palm FA would have an effect on the concentrations of FA at the $s n-2$ or $s n-1(3)$ positions in TAG structures. Because fat supplementation influenced TAG composition to a greater extent than protein supplementation in this study, positional distribution analysis was performed only for diets without protein supplementation (i.e., LP-LF and LP-HF). Moreover, based on the fact that the major FA in milk fat will have the largest effect on the physical properties of milk fat, this discussion will mainly focus on the variation in inter- and intrapositional distributions of these FA in milk TAG structures. Major FA were previously defined as FA with total concentrations $>0.5 \%$ (Jensen, 2002). In this study they refer to even-numbered FA C4:0 to the C14:0, C14:1 cis-9, C15:0, C16:0, C16:1 cis-9, C17:0, C18:0, C18:1 cis-9, C18:1 cis-9,trans-11 (CLA), C18:2 cis-9,12 (linoleic acid), and C18:3 cis-9,12,15 (linolenic acid) as major FA (Nichols et al., 2018).

Using the interpositional distribution, the stereolocation preference of a FA over the $3 s n$-positions in the TAG structure can be determined. If a FA would be positioned randomly across the $s n-2$ and $s n-1(3)$ positions in the TAG structure, $s n-2$ would hold $33.33 \%$ and $s n-1(3)$ would hold $66.67 \%$ (2 of the 3 positions) of that FA. Therefore, distribution of a FA above $33.33 \%$ at $s n-2$ or above $66.67 \%$ at $s n-1(3)$ indicates that the enzymes responsible for the esterification of FA at these positions have a preference for that particular FA. Based on a one-sample $t$-test performed between the obtained proportion for each treatment and the random hypothetical proportions, the esterification preference of a FA at both positions over the TAG structure was determined (Supplemental Table S3, https://doi .org/10.4121/18318725.v1). For the major FA, regardless of dietary fat supplementation, our results show a FA esterification preference at the $s n-1(3)$ positions for 
Table 2. Interpositional distribution (mol \%) of fatty acid (FA) in milk fat triacylglycerol structures of lactating dairy cows supplemented with fat

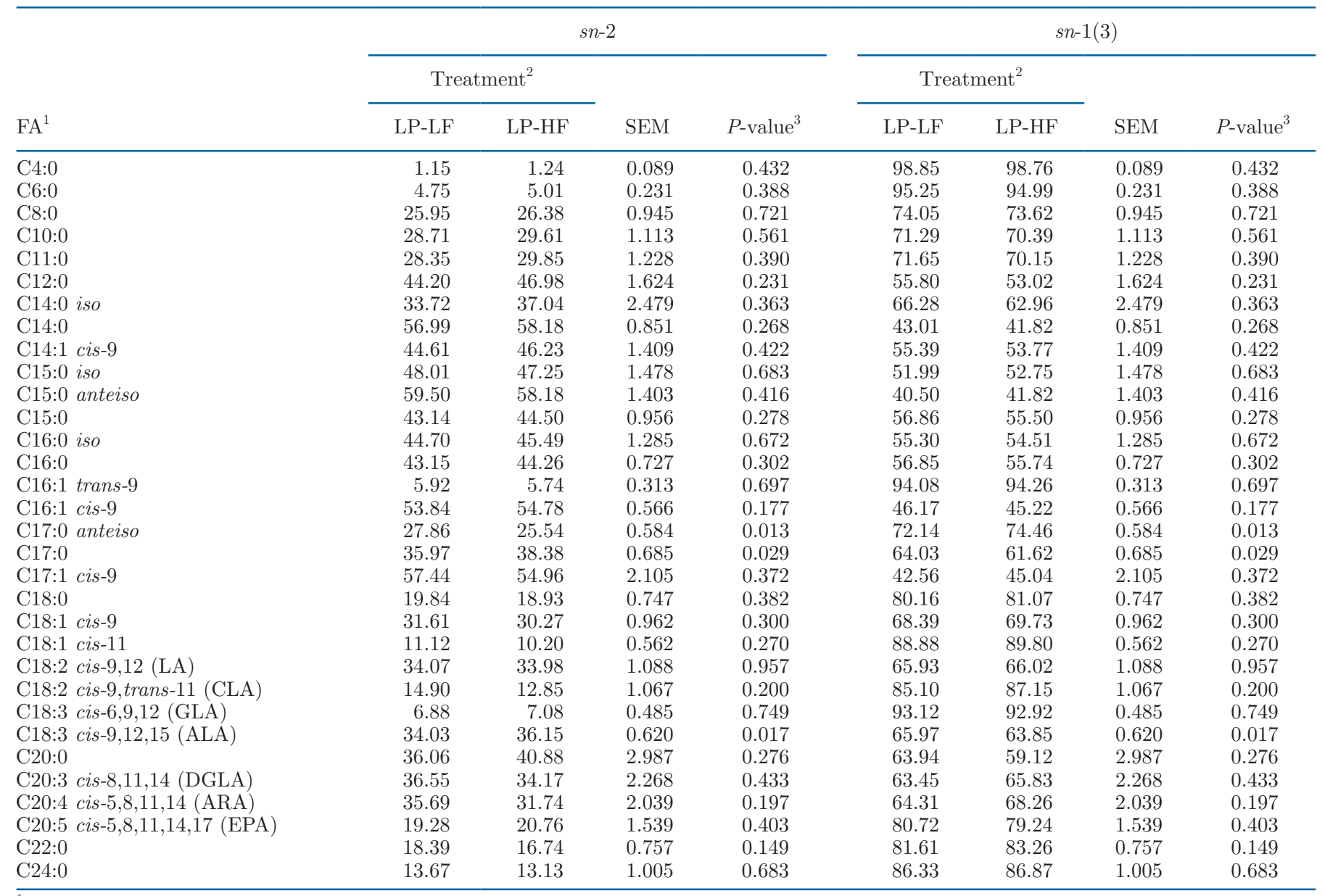

${ }^{1} \mathrm{LA}=$ linoleic acid; GLA $=\gamma$-linolenic acid; ALA = linolenic acid; DGLA = dihomo- $\gamma$-linolenic acid; ARA = arachidonic acid; EPA $=$ eicosapentaenoic acid.

${ }^{2}$ LP-LF $=$ low protein, low fat; LP-HF = low protein, high fat. High fat supplementation consisted of rumen-inert hydrogenated palm fatty acids. For all treatments $\mathrm{n}=14$.

${ }^{3} P$-values correspond to the effect of fat on the fatty acid positional distribution at the $s n-2$ and $s n-1(3)$ positions.

C4:0 to C10:0, C18:0, and C18:2 cis-9,trans-11 (CLA; $P<0.050)$. On the other hand, the major FA that were preferentially esterified at the $s n-2$ position were C12:0, C14:0, C14:1 cis-9, C15:0, C16:0, C16:1 cis-9, and $\mathrm{C} 17: 0(P<0.050)$. These stereolocation preferences of the major FA are in line with previous studies (Jensen, 2002; Blasi et al., 2008; Tzompa-Sosa et al., 2014). Interestingly, the proportions of most FA (except for $\mathrm{C} 17: 0$ anteiso, $\mathrm{C} 17: 0$, and $\mathrm{C} 18: 3$ cis-9,12,15) over the TAG structure at both $s n-2$ and $s n-1(3)$ positions were not affected by fat supplementation $(P>0.050$; Table 2), indicating that the stereolocation of most FA did not change when hydrogenated palm FA were fed. Tzompa-Sosa et al. (2014) identified significant variations in the FA proportions at the $s n-2$ position of C14:0, C16:0, C18:1 cis-9, and SLCFA in the TAG structure that varied with changes in $\mathrm{C} 16: 0$ content in milk fat. Our study may not have found such an effect due to the smaller variation in the total C16:0 in milk fat compared with the study by Tzompa-Sosa et al. (2014).

Regardless of fat supplementation, C14:0, C16:0, and $\mathrm{C} 18: 1 \mathrm{cis}-9$ had the highest relative concentrations at the $s n-2$ position in the TAG structure, and C4:0, C16:0, and C18:1 cis-9 had the highest concentrations at the $s n-1(3)$ positions (intrapositional distribution; Table 3). These results are in accordance with previous studies (Blasi et al., 2008; Tzompa-Sosa et al., 2014; Watanabe et al., 2015). At the $s n-2$ position, most FA were affected in response to fat supplementation with the exceptions of $\mathrm{C} 4: 0, \mathrm{C} 6: 0, \mathrm{C} 14: 1$ cis-9, C16:1 cis-9, C18:1 cis-9, C18:1 cis-11, and some PUFA (Table 3). Among the FA at the $s n-2$ position that were affected, only $\mathrm{C} 16: 0$ and $\mathrm{C} 18: 0$ increased $(P=0.003$ and $P=$ 
Table 3. Intrapositional distribution (mol \%) of fatty acids (FA) in milk fat triacylglycerol structures of lactating dairy cows supplemented with fat

\begin{tabular}{|c|c|c|c|c|c|c|c|c|}
\hline $\mathrm{FA}^{1}$ & \multicolumn{4}{|c|}{$s n-2$} & \multicolumn{4}{|c|}{$s n-1(3)$} \\
\hline C4:0 & 0.36 & 0.39 & 0.027 & 0.315 & 15.29 & 15.57 & 0.220 & 0.371 \\
\hline C6:0 & 0.71 & 0.70 & 0.033 & 0.850 & 7.05 & 6.61 & 0.095 & 0.004 \\
\hline $\mathrm{C} 8: 0$ & 1.79 & 1.59 & 0.062 & 0.011 & 2.55 & 2.23 & 0.058 & 0.002 \\
\hline C12:0 & 5.41 & 4.54 & 0.167 & 0.003 & 3.41 & 2.61 & 0.130 & $<0.001$ \\
\hline $\mathrm{C} 14: 0$ iso & 0.20 & 0.16 & 0.007 & 0.002 & 0.21 & 0.15 & 0.014 & 0.010 \\
\hline C14:0 & 20.29 & 17.71 & 0.414 & $<0.001$ & 7.65 & 6.39 & 0.197 & $<0.001$ \\
\hline C14:1 cis-9 & 1.53 & 1.38 & 0.073 & 0.162 & 0.96 & 0.84 & 0.063 & 0.199 \\
\hline $\mathrm{C} 15: 0$ iso & 0.38 & 0.31 & 0.010 & $<0.001$ & 0.21 & 0.18 & 0.010 & 0.054 \\
\hline C15:0 anteiso & 0.78 & 0.63 & 0.020 & $<0.001$ & 0.26 & 0.23 & 0.013 & 0.092 \\
\hline C15:0 & 1.36 & 1.14 & 0.033 & 0.001 & 0.90 & 0.71 & 0.024 & $<0.001$ \\
\hline $\mathrm{C} 17: 0$ & 0.48 & 0.43 & 0.015 & 0.001 & 0.43 & 0.34 & 0.010 & $<0.001$ \\
\hline C17:1 cis-9 & 0.31 & 0.26 & 0.013 & 0.001 & 0.11 & 0.11 & 0.007 & 0.652 \\
\hline C18:0 & 4.38 & 4.96 & 0.219 & 0.012 & 8.85 & 10.70 & 0.340 & 0.002 \\
\hline $\mathrm{C} 18: 1$ cis -9 & 14.04 & 14.89 & 0.680 & 0.330 & 15.13 & 16.98 & 0.371 & $<0.001$ \\
\hline C18:1 cis-11 & 0.16 & 0.14 & 0.012 & 0.165 & 0.63 & 0.61 & 0.033 & 0.667 \\
\hline $\mathrm{C} 18: 2$ cis-9,12 (LA) & 1.66 & 1.47 & 0.059 & 0.035 & 1.60 & 1.46 & 0.063 & 0.122 \\
\hline C18:2 cis-9,trans-11 (CLA) & 0.28 & 0.21 & 0.015 & 0.003 & 0.84 & 0.74 & 0.057 & 0.219 \\
\hline C18:3 cis-6,9,12 (GLA) & 0.04 & 0.04 & 0.002 & 0.821 & 0.24 & 0.24 & 0.008 & 0.891 \\
\hline C18:3 cis-9,12,15 (ALÁ) & 0.39 & 0.33 & 0.012 & 0.005 & 0.38 & 0.29 & 0.012 & $<0.001$ \\
\hline C20:0 & 0.030 & 0.027 & 0.001 & 0.006 & 0.029 & 0.022 & 0.003 & 0.109 \\
\hline C20:3 cis-8,11,14 (DGLA) & 0.053 & 0.053 & 0.004 & 0.947 & 0.048 & 0.055 & 0.007 & 0.472 \\
\hline C20:4 cis-5,8,11,14 (ARA) & 0.025 & 0.021 & 0.001 & 0.061 & 0.022 & 0.024 & 0.002 & 0.583 \\
\hline C20:5 cis-5,8,11,14,17 (EPA) & 0.020 & 0.019 & 0.001 & 0.555 & 0.042 & 0.038 & 0.002 & 0.025 \\
\hline
\end{tabular}

${ }^{1} \mathrm{LA}=$ linoleic acid; GLA $=\gamma$-linolenic acid; ALA = linolenic acid; DGLA = dihomo- $\gamma$-linolenic acid; ARA = arachidonic acid; EPA $=$ eicosapentaenoic acid.

${ }^{2} \mathrm{LP}-\mathrm{LF}=$ low protein, low fat; LP-HF = low protein, high fat. High fat supplementation consisted of rumen-inert hydrogenated palm fatty acids. For all treatments $\mathrm{n}=14$.

${ }^{3} P$-values correspond to the effect of fat on the fatty acid positional distribution at the $s n-2$ and $s n-1(3)$ positions.

0.012, respectively), whereas all the other FA decreased in response to fat supplementation. Moreover, most FA at the $s n-1(3)$ positions also showed changes upon fat supplementation with the exceptions of a few FA, including the major FA C4:0, C14:1 cis-9, C16:0, C18:2 cis-9,12 (linoleic acid), and CLA (Table 3). Among the FA that changed at the $s n-1(3)$ positions, only C18:0 and C18:1 cis-9 increased $(P \leq 0.002)$, whereas the other FA all decreased in response to fat supplementation (Table 3). It appears that the increased concentrations of $\mathrm{C} 16: 0, \mathrm{C} 18: 0$, and $\mathrm{C} 18: 1$ cis-9 in the TAG, likely as a result of increased concentration of C16:0 and C18:0 in the diet and subsequent uptake by the mammary gland as well as by stearoyl-CoA desaturase activity on C18:0 (Corl et al., 2001), increased the abundance of $\mathrm{C} 16: 0$ only at $s n-2, \mathrm{C} 18: 1$ cis-9 only at $s n-1(3)$, and
C18:0 at both the $s n-2$ and $s n-1(3)$ positions of the TAG structures.

As it is the most abundant FA in milk fat, the stereolocation of $\mathrm{C} 16: 0$ at the $s n-2$ position in the TAG structure is important for fat digestion and absorption, particularly in infants (Innis, 2011; Yaron et al., 2013). Greater abundance of $\mathrm{C} 16: 0$ at the $s n-2$ position in TAG improves absorption of free FA and calcium from milk products by infants (Innis, 2011). In contrast, hydrolysis of TAG that contain high concentrations of SLCFA, such as C16:0 and C18:0, at the sn-1(3) positions results in the release of free FA that bind with calcium and other dietary minerals, resulting in indigestible calcium complexes (Small, 1991; Ramírez et al., 2001; Mu and Høy, 2004). Formation of these complexes decreases fat and mineral absorption and 
Table 4. Milk solid fat content (\% of milk fat) at $0,10,20,25,30$, and $40^{\circ} \mathrm{C}$ of lactating dairy cows supplemented with protein and fat

\begin{tabular}{|c|c|c|c|c|c|c|c|c|}
\hline \multirow[b]{2}{*}{ Temperature $\left({ }^{\circ} \mathrm{C}\right)$} & \multicolumn{4}{|c|}{ Treatment $^{1}$} & \multirow[b]{2}{*}{ SEM } & \multicolumn{3}{|c|}{$P$-value } \\
\hline & LP-LF & HP-LF & LP-HF & HP-HF & & Protein & Fat & Protein $\times$ fat \\
\hline 20 & 21.2 & 20.0 & 26.0 & 24.1 & 0.95 & 0.101 & $<0.001$ & 0.733 \\
\hline 25 & 12.3 & 11.3 & 14.8 & 13.9 & 0.57 & 0.099 & $<0.001$ & 0.950 \\
\hline 30 & 6.6 & 5.8 & 8.8 & 8.1 & 0.36 & 0.041 & $<0.001$ & 0.903 \\
\hline
\end{tabular}

${ }^{1}$ LP-LF = low protein, low fat; HP-LF = high protein, low fat; LP-HF = low protein, high fat; HP-HF = high protein, high fat. High protein supplementation consisted of a 50:50 mixture of rumen-protected soybean meal and rapeseed meal. High fat supplementation consisted of rumeninert hydrogenated palm fatty acids. For all treatments $\mathrm{n}=14$.

causes hard stool and constipation in infants (Kennedy et al., 1999; Mu and Høy, 2004; Yaron et al., 2013). In addition, several studies on fat digestion in infants have reported increased absorption of fat and minerals when most of the C18:1 cis-9 was esterified at the sn1(3) positions ( $\mathrm{Mu}$ and $\mathrm{Høy}, 2004$; Innis, 2011). Our results suggest that supplementing dairy cattle diets with hydrogenated palm FA results in milk TAG structures richer in C16:0 at sn-2, C18:1 cis-9 at sn-1(3), and C18:0 at both $s n-2$ and $s n-1(3)$ positions. Therefore, FA and mineral absorption may be enhanced upon consumption of dairy products containing TAG structures from milk produced by cattle consuming high levels of hydrogenated palm FA. However, the increased concentration of $\mathrm{C} 18: 0$ at the $s n-1(3)$ positions in response to fat supplementation may instead decrease the absorption of FA and minerals, hindering the beneficial effect caused by $\mathrm{C} 16: 0$ at the $s n-2$ and C18:1 cis-9 at the $s n-1(3)$ positions. Overall, we have shown that by increasing the concentration of specific SLCFA (C16:0 and $\mathrm{C} 18: 0)$ in the diet of dairy cattle, the concentrations of these FA or their desaturation products at the $s n-2$ and $s n-1(3)$ positions in the TAG structure can be changed. These findings may be of interest for developers of infant formula or other specialty dairy products.

\section{Variation in SFC}

Variations in TAG composition are known to influence milk SFC. Hence, due to the large variations in TAG composition in response to fat supplementation in this study, alterations in milk SFC were expected. Milk SFC was not affected by protein $\times$ fat interactions (Table 4), increased at 20,25 , and $30^{\circ} \mathrm{C}$ in response to fat supplementation $(P<0.001)$, and decreased at $30^{\circ} \mathrm{C}$ in response to protein supplementation $(P=$ 0.041). These effects on SFC may be explained by the changes in TAG composition observed in response to fat and protein supplementation. Hydrogenated palm FA supplementation increased the formation of the HMW TAG CN50 and CN52. The HMW TAG CN50 correlated positively with $\mathrm{C} 16: 0(\mathrm{r}=0.59)$ and the HMW TAG CN52 correlated positively with C18:0 (r $=0.61$ ), whereas both TAG groups CN50 and CN52 correlated negatively with most de novo FA C6:0 to C15:0 ( $r \leq-0.41$; Supplemental Table S2). Both C16:0 and C18:0 have higher melting points than FA of a shorter chain length, thus leading to higher melting points of the HMW TAG CN50 and CN52 (Knothe and Dunn, 2009). Therefore, the higher concentration of HMW TAG species in response to fat supplementation, especially saturated HMW TAG species, may explain the increased $\mathrm{SFC}$ at 20,25 , and $30^{\circ} \mathrm{C}$ in response to fat supplementation. This is supported by Smiddy et al. (2012) who showed that concentrations of HMW CN50, CN52, and CN54 determined the variation in the melting profiles of milk fat of several animal species, including bovine milk.

We hypothesize that the decrease in milk SFC at $30^{\circ} \mathrm{C}$ in response to protein supplementation is related to the increased concentrations of PUFA in milk fat (Nichols et al., 2018) and the increased formation of total diunsaturated TAG species and MMW polyunsaturated TAG species (Figure 1; Supplemental Table S1). The PUFA have a lower melting point due to the large number of $\mathrm{DB}$ in their structures, and thus their esterification in TAG species will lead to a decrease in the melting point of the resulting TAG. Similar to our study, previous studies that assessed the effect of feeding UFA to dairy cows on milk TAG composition and SFC showed that when the dietary content of PUFA increased, SFC measured at 4 to $30^{\circ} \mathrm{C}$ decreased (Precht and Frede, 1994; Couvreur et al., 2006; Smet et al., 2010).

Increased milk SFC at 20, 25, and $30^{\circ} \mathrm{C}$ may have negative effects on milk fat processing and its application as an ingredient in dairy-based food products. For example, there may be implications and adjustments required for the processing conditions required for milk fat fractionation to obtain stearin $(\mathrm{SFC} \geq 55 \%$, melting temperature $\geq 20^{\circ} \mathrm{C}$ ) and olein ( $\mathrm{SFC}<55 \%$, melting temperature $\leq 19^{\circ} \mathrm{C}$ ), which are fractions used 
in several food applications (Deffense, 1993; Mohan et al., 2021). Moreover, milk SFC at 20,25 , and $30^{\circ} \mathrm{C}$ is known to determine texture and mouthfeel properties of milk fat-containing food products, as well as their table-top quality properties (e.g., structure and stability of butter and its resistance to oil exudation; Deffense, 1993; Mohan et al., 2021). Based on these results, the effect of feeding hydrogenated palm FA to dairy cows on milk fat properties and how this affects quality and consumer acceptability of high fat dairy products should be considered holistically by dairy nutritionists, processors, and product manufacturers.

\section{CONCLUSIONS}

This study investigated the effect of supplementing the diet of dairy cattle with protein from rumen-protected sources and fat from hydrogenated palm FA on milk TAG composition and structure, and milk SFC. Fat supplementation modified these parameters more than protein supplementation. In response to fat supplementation, the concentrations of LMW and MMW TAG decreased and the concentrations of HMW TAG increased. Fat supplementation also increased the formation of TAG with greater proportions of C16:0 and C18:0 at the $s n-2$ position and C18:0 and C18:1 cis-9 at the $s n-1(3)$ positions in their structures. Fat supplementation increased milk SFC at 20,25 , and $30^{\circ} \mathrm{C}$, correlating with increased abundance of HMW TAG species probably containing more C16:0 and C18:0. These changes in TAG composition and structure, and milk SFC may affect nutritional and physiochemical quality of dairy products originating from the milk fat produced by cattle consuming rations supplemented with hydrogenated palm FA.

\section{ACKNOWLEDGMENTS}

We gratefully acknowledge financial support from the Colombian National Administrative Department for Science, Technology and Innovation (COLCIENCIAS). Milk samples were obtained from a research project conducted by Wageningen University and Research (Wageningen Livestock Research, Wageningen, the Netherlands), commissioned and funded by the Ministry of Agriculture, Nature and Food Quality (The Hague, the Netherlands) within the framework of Policy Support Research theme "Feed-4Foodure" (BO-31.03-005001; TKI-AF12039B), and by the Vereniging Diervoederonderzoek Nederland (Rijswijk, the Netherlands). We also acknowledge the R\&D facilities of Friesland Campina (Wageningen, the Netherlands) for the use of their NMR for the solid fat content analysis. Finally, we acknowledge Michiel Wijtten from Wageningen Food
Safety Research at Wageningen University and Research (Wageningen, the Netherlands) for performing the FA and triacylglycerol composition analyses with GC-FID. The authors have not stated any conflicts of interest.

\section{REFERENCES}

AOCS. 2017. Solid fat content (SFC) by low-resolution nuclear magnetic resonance, Direct method. Pages 1-65 in Official Method Cd 16b-93. American Oil Chemists' Society.

AOCS. 2019. Determination of the composition of fatty acids at the 2-position of oils and fats - Enzymatic transesterification method using Candida Antarctica lipase. Pages 1-28 in Joint JOCA/ AOCS Official Method Ch 3a-19. American Oil Chemists' Society.

Ashes, J. R., S. K. Gulati, and T. W. Scott. 1997. Potential to alter the content and composition of milk fat through nutrition. J. Dairy Sci. 80:2204-2212. https://doi.org/10.3168/jds.S0022 -0302(97)76169-1.

Banks, W., J. L. Clapperton, D. D. Muir, and A. K. Girdler. 1989. Whipping properties of cream in relation to milk composition. J. Dairy Res. 56:97-105. https://doi.org/10.1017/S0022029900026261.

Baumgard, L. H., B. A. Corl, D. A. Dwyer, A. Saebø, and D. E. Bauman. 2000. Identification of the conjugated linoleic acid isomer that inhibits milk fat synthesis. Am. J. Physiol. Regul. Integr Comp. Physiol. 278:R179-R184. https://doi.org/10.1152/ajpregu 2000.278.1.R179.

Blasi, F., D. Montesano, M. De Angelis, A. Maurizi, F. Ventura, L. Cossignani, M. S. Simonetti, and P. Damiani. 2008. Results of stereospecific analysis of triacylglycerol fraction from donkey, cow, ewe, goat and buffalo milk. J. Food Compos. Anal. 21:1-7. https:/ /doi.org/10.1016/j.jfca.2007.06.005.

Corl, B. A., L. H. Baumgard, D. A. Dwyer, J. M. Griinari, B. S. Phillips, and D. E. Bauman. 2001. The role of $\Delta 9$-desaturase in the production of cis-9, trans-11 CLA. J. Nutr. Biochem. 12:622-630. https://doi.org/10.1016/S0955-2863(01)00180-2.

Couvreur, S., C. Hurtaud, C. Lopez, L. Delaby, and J. L. Peyraud. 2006. The linear relationship between the proportion of fresh grass in the cow diet, milk fatty acid composition, and butter properties. J. Dairy Sci. 89:1956-1969. https://doi.org/10.3168/jds.S0022 -0302(06)72263-9.

Deffense, E. 1993. Milk fat fractionation today: A review. J. Am. Oil Chem. Soc. 70:1193-1201. https://doi.org/10.1007/BF02564225.

DePeters, E. J., J. B. German, S. J. Taylor, S. T. Essex, and H. PerezMonti. 2001. Fatty acid and triglyceride composition of milk fat from lactating Holstein cows in response to supplemental canola oil. J. Dairy Sci. 84:929-936. https://doi.org/10.3168/jds.S0022 -0302(01)74550-X.

Fahy, E., S. Subramaniam, H. A. Brown, C. K. Glass, A. H. Merrill Jr., R. C. Murphy, C. R. H. Raetz, D. W. Russell, Y. Seyama, W. Shaw, T. Shimizu, F. Spener, G. van Meer, M. S. VanNieuwenhze, S. H. White, J. L. Witztum, and E. A. Dennis. 2005. A comprehensive classification system for lipids. J. Lipid Res. 46:839-861. https://doi.org/10.1194/jlr.E400004-JLR200.

Gibb, S., and K. Strimmer. 2012. MALDIquant: A versatile R package for the analysis of mass spectrometry data. Bioinformatics 28:2270-2271. https://doi.org/10.1093/bioinformatics/bts447.

Gresti, J., M. Bugaut, C. Maniongui, and J. Bezard. 1993. Composition of molecular species of triacylglycerol in bovine milk fat. J. Dairy Sci. 76:1850-1869. https://doi.org/10.3168/jds.S0022 -0302(93)77518-9.

Harvatine, K. J. 2021. Perspective: A commentary on the effect of palmitic acid feeding on thermal properties of milk fat. J. Dairy Sci. 104:9377-9379. https://doi.org/10.3168/jds.2021-20390.

Innis, S. M. 2011. Dietary triacylglycerol structure and its role in infant nutrition. Adv. Nutr. 2:275-283. https://doi.org/10.3945/an .111 .000448

ISO. 2002. Milk Fat - Preparation of Fatty Acid Methyl Esters. Pages 1-68. Vol. ISO 15884:2002 (IDF 182:2002). International Organization for Standardization. 
ISO. 2010. Milk and Milk Products - Determination of Milk Fat Purity by Gas Chromatographic Analysis of Triglycerides (Reference Method). Pages 1-140. Vol. ISO 17678:2010 (IDF 202:2010). International Organization for Standardization.

ISO. 2015. Milk, Milk Products, Infant Formula and Adult Nutritionals-Determination of Fatty Acids Composition - Capillary Gas Chromatographic Method. Pages 1-45. Vol. ISO 16958:2015 (IDF 231:2015). International Organization for Standardization.

Jacobs, A. A. A., J. van Baal, M. A. Smits, H. Z. H. Taweel, W. H. Hendriks, A. M. van Vuuren, and J. Dijkstra. 2011. Effects of feeding rapeseed oil, soybean oil, or linseed oil on stearoyl-CoA desaturase expression in the mammary gland of dairy cows. J. Dairy Sci. 94:874-887. https://doi.org/10.3168/jds.2010-3511.

Jenkins, T. C., and M. A. McGuire. 2006. Major advances in nutrition: Impact on milk composition. J. Dairy Sci. 89:1302-1310. https:// doi.org/10.3168/jds.S0022-0302(06)72198-1.

Jensen, R. G. 2002. The composition of bovine milk lipids: January 1995 to December 2000. J. Dairy Sci. 85:295-350. https://doi.org/ 10.3168/jds.S0022-0302(02)74079-4.

Kennedy, K., M. S. Fewtrell, R. Morley, R. Abbott, P. T. Quinlan, J. C. K. Wells, J. G. Bindels, and A. Lucas. 1999. Double-blind, randomized trial of a synthetic triacylglycerol in formula-fed term infants: Effects on stool biochemistry, stool characteristics, and bone mineralization. Am. J. Clin. Nutr. 70:920-927. https://doi .org/10.1093/ajcn/70.5.920.

Knothe, G., and R. O. Dunn. 2009. A comprehensive evaluation of the melting points of fatty acids and esters determined by differential scanning calorimetry. J. Am. Oil Chem. Soc. 86:843-856. https:// doi.org/10.1007/s11746-009-1423-2.

Larsen, M. K., K. K. Andersen, N. Kaufmann, and L. Wiking. 2014. Seasonal variation in the composition and melting behavior of milk fat. J. Dairy Sci. 97:4703-4712. https://doi.org/10.3168/jds.2013 -7858 .

Liu, Z., C. Li, J. Pryce, and S. Rochfort. 2020. Comprehensive characterization of bovine milk lipids: Phospholipids, sphingolipids, glycolipids and ceramides. J. Agric. Food Chem. 68:6726-6738. https: //doi.org/10.1021/acs.jafc.0c01604.

Marangoni, A. G., and S. M. Ghazani. 2021. Perspective: A commentary on elevated palmitic acid levels in Canadian butter and their relationship to butter hardness. J. Dairy Sci. 104:9380-9382. https: //doi.org/10.3168/jds.2021-20469.

Mohan, M. S., T. F. O'Callaghan, P. Kelly, and S. A. Hogan. 2021. Milk fat: Opportunities, challenges and innovation. Crit. Rev. Food Sci. Nutr. 61:2411-2443. https://doi.org/10.1080/10408398 2020.1778631 .

Mu, H., and C. E. Høy. 2004. The digestion of dietary triacylglycerols. Prog. Lipid Res. 43:105-133. https://doi.org/10.1016/S0163 -7827(03)00050-X.

National Research Council (NRC). 2001. Nutrient Requirements of Dairy Cattle. National Academies Press.

Nichols, K., A. Bannink, S. Pacheco, H. J. van Valenberg, J. Dijkstra, and H. van Laar. 2018. Feed and nitrogen efficiency are affected differently but milk lactose production is stimulated equally when isoenergetic protein and fat is supplemented in lactating dairy cow diets. J. Dairy Sci. 101:7857-7870. https://doi.org/10.3168/jds .2017-14276.

Nichols, K., H. van Laar, A. Bannink, and J. Dijkstra. 2019. Mammary gland utilization of amino acids and energy metabolites differs when dairy cow rations are isoenergetically supplemented with protein and fat. J. Dairy Sci. 102:1160-1175. https://doi.org/10 $.3168 /$ jds.2018-15125.

NorAini, I., M. S. Embong, A. Aminah, A. R. Md. Ali, and C. H. C. Maimon. 1995. Physical characteristics of shortenings based on modified palm oil, milkfat and low melting milkfat fraction. Eur. J. Lipid Sci Technol. 97:253-260. https://doi.org/10.1002/ lipi.19950970704.

Pacheco-Pappenheim, S., S. Yener, J. M. L. Heck, J. Dijkstra, and H. J. F. van Valenberg. 2021. Seasonal variation in fatty acid and triacylglycerol composition of bovine milk fat. J. Dairy Sci. 104:8479-8492. https://doi.org/10.3168/jds.2020-19856.
Pacheco-Pappenheim, S., S. Yener, H. J. F. van Valenberg, D. A Tzompa-Sosa, and H. Bovenhuis. 2019. The DGAT1 K232A polymorphism and feeding modify milk fat triacylglycerol composition. J. Dairy Sci. 102:6842-6852. https://doi.org/10.3168/jds.2019 -16554 .

Precht, D., and E. Frede. 1994. Determination of the solid fat content in milk fat by gas chromatographic triglyceride analysis. Eur. J. Lipid Sci. Technol. 96:324-330. https://doi.org/10.1002/lipi 19940960902

Rabiee, A. R., K. Breinhild, W. Scott, H. M. Golder, E. Block, and I. J. Lean. 2012. Effect of fat additions to diets of dairy cattle on milk production and components: A meta-analysis and metaregression. J. Dairy Sci. 95:3225-3247. https://doi.org/10.3168/ jds.2011-4895.

Ramírez, M., L. Amate, and A. Gil. 2001. Absorption and distribution of dietary fatty acids from different sources. Early Hum. Dev. 65:S95-S101. https://doi.org/10.1016/S0378-3782(01)00211-0.

Schiller, J., R. Süß, J. Arnhold, B. Fuchs, J. Leßig, M. Müller, M. Petković, H. Spalteholz, O. Zschörnig, and K. Arnold. 2004. Matrix-assisted laser desorption and ionization time-of-flight (MALDI-TOF) mass spectrometry in lipid and phospholipid research. Prog. Lipid Res. 43:449-488. https://doi.org/10.1016/j.plipres .2004.08.001.

Small, D. M. 1991. The effects of glyceride structure and absorption and metabolism. Annu. Rev. Nutr. 11:413-434. https://doi.org/10 .1146/annurev.nu.11.070191.002213.

Smet, K., K. Coudijzer, E. Fredrick, S. De Campeneere, J. De Block, J. Wouters, K. Raes, and K. Dewettinck. 2010. Crystallization behavior of milk fat obtained from linseed-fed cows. J. Dairy Sci 93:495-505. https://doi.org/10.3168/jds.2009-2588.

Smiddy, M. A., T. Huppertz, and S. M. van Ruth. 2012. Triacylglycerol and melting profiles of milk fat from several species. Int. Dairy J. 24:64-69. https://doi.org/10.1016/j.idairyj.2011.07.001.

Tzompa-Sosa, D. A., P. P. Meurs, and H. J. F. van Valenberg. 2018. Triacylglycerol profile of summer and winter bovine milk fat and the feasibility of triacylglycerol fragmentation. Eur. J. Lipid Sci. Technol. 120:1700291. https://doi.org/10.1002/ejlt.201700291.

Tzompa-Sosa, D. A., G. A. van Aken, A. C. M. van Hooijdonk, and H. J. F. van Valenberg. 2014. Influence of C16:0 and long-chain saturated fatty acids on normal variation of bovine milk fat triacylglycerol structure. J. Dairy Sci. 97:4542-4551. https://doi.org/ $10.3168 /$ jds.2014-7937.

Watanabe, Y., S. Sato, M. Asada, T. Arishima, Y. Iida, J. Imagi, K. Saito, T. Sano, A. Sasaki, R. Sasaki, C. Sato, T. Shibuya, Y. Tsukahara, T. Nagai, T. Fukazawa, R. Hori, R. Homma, Y. Miyazaki, A. Yamashita, K. Yoshinaga, and S. Watanabe. 2015. Enzymatic analysis of positional fatty acid distributions in triacylglycerols by 1(3)-selective transesterification with Candida antarctica lipase b: A collaborative study. J. Oleo Sci. 64:1193-1205. https://doi.org/ $10.5650 /$ jos.ess 15182.

Yaron, S., D. Shachar, L. Abramas, A. Riskin, D. Bader, I. Litmanovitz, F. Bar-Yoseph, T. Cohen, L. Levi, Y. Lifshitz, R. Shamir, and R. Shaoul. 2013. Effect of high $\beta$-palmitate content in infant formula on the intestinal microbiota of term infants. J. Pediatr. Gastroenterol. Nutr. 56:376-381. https://doi.org/10.1097/MPG .0b013e31827e1ee2.

Yener, S., and H. J. F. van Valenberg. 2019. Characterisation of triacylglycerols from bovine milk fat fractions with MALDI-TOF-MS fragmentation. Talanta 204:533-541. https://doi.org/10.1016/j .talanta.2019.06.013.

\section{ORCIDS}

Sara Pacheco-Pappenheim @ https://orcid.org/0000-0003-1579-2402 Sine Yener @ https://orcid.org/0000-0001-8320-7135 Kelly Nichols @ https://orcid.org/0000-0001-6062-7460 Jan Dijkstra @ https://orcid.org/0000-0003-3728-6885 Kasper Hettinga @ https://orcid.org/0000-0002-9017-4447 Hein J. F. van Valenberg @ ittps://orcid.org/0000-0002-7228-2073 